\title{
Crescimento e produção de óleo essencial de Melissa officinalis L. nas condições climáticas de Montes Claros - MG
}

\author{
Messulan Rodrigues Meira* \\ Sara Anizelli Manganotti \\ Ernane Ronie Martins \\ Laboratório de Plantas Medicinais, Instituto de Ciências Agrárias \\ Universidade Federal de Minas Gerais \\ CEP 39404-006, Montes Claros - MG, Brasil \\ *Autor para correspondência \\ messulan@hotmail.com
}

Submetido em 10/03/2010

Aceito para publicação em 08/10/2010

\section{Resumo}

O objetivo deste trabalho foi avaliar o crescimento e teor de óleo essencial de Melissa officinalis nas condições climáticas de Montes Claros - MG. O experimento foi conduzido de maio a novembro de 2009. O delineamento experimental foi o inteiramente casualizado (DIC) com quatro tratamentos e cinco repetições. Na primeira análise, foi avaliado o efeito da época de colheita sobre a produção de biomassa e óleo essencial. Na segunda análise, foi avaliada a produção de biomassa e óleo essencial após 30 dias da colheita da análise anterior. Os dados foram submetidos à análise de regressão, utilizando o software SAEG. Dos resultados encontrados, o primeiro corte aos 33 dias favoreceu a produção de massa seca. A melhor época de produção de óleo essencial em melissa ocorreu na rebrota 30 dias após o primeiro corte da planta mais jovem. Com este trabalho concluiuse que a colheita mais precoce nas condições do Norte de Minas favorece a produção de biomassa e apresenta teor de óleo essencial similar às demais colheitas.

Palavras-chave: Biomassa, Metabólitos secundários, Plantas medicinais

\section{Abstract}

Growth and production of essential oil of Lemon Balm (Melissa officinalis L.). The objective of this study was to evaluate the growth and essential oil production of Melissa officinalis in the climatic conditions of Montes Claros - MG. The experiment was conducted from May to November 2009. The experimental design was completely randomized (CRD) with four treatments and five repetitions. In the first analysis, the effect of harvesting time on the biomass and essential oil was evaluated. In the second analysis, the production of biomass and essential oil after 30 days of harvest of the previous study was evaluated. The data were submitted to regression analysis using the software SAEG. From the results, the first cut at 33 days, increased the percentage of dry matter, and the best time of production of the Lemon Balm's essential oil occurred during regrowth, 30 days after the first harvest of the younger plant. This study concluded that the early harvest in the conditions of northern Minas Gerais favors the production of biomass and feature content of essential oil similar to other crops.

Key words: Biomass, Medicinal plants, Secondary metabolism 


\section{Introdução}

A melissa (Melissa officinalis L.), conhecida como erva-cidreira verdadeira, também possui outros nomes populares como chá-de-França, cidrilha, citronelamenor, erva-luísa, e melissa romana. Pertence à família Lamiaceae, de origem Asiática e Européia, é cultivada no Brasil a mais de um século. Possui características semelhantes à hortelã-pimenta (Mentha piperita Linn.), é perene, herbácea, rizomatosa, podendo variar de 20 a $80 \mathrm{~cm}$ e 30 a $100 \mathrm{~cm}$ de altura, possui caule quadrangular dispondo-se em tufos, herbáceos, ereto, piloso e aromático, ramificando-se desde a base formando touceiras com raízes fibrosas. Suas folhas membranáceas são verde-escura na parte superior e verde-clara na parte inferior atingindo de 3 a $6 \mathrm{~cm}$ de comprimento, são grandes, pecioladas, opostas, lanceoladas, ovais e pilosas, serrilhadas e com nervuras bem salientes (CORREA JÚNIOR et al., 1991; COUTO, 2006).

Suas flores possuem cor branca ou amarela, podendo se tornar rosadas com o passar do tempo, reunidas em fascículos de 2 a 6 unidades com florescimento de outubro a março na Europa, não florescendo no Brasil devido às condições climáticas (LORENZI; MATOS, 2002; BLANK et al., 2005). Em regiões de maior altitude como o sul, as flores possuem coloração creme. Toda a planta é melífera, exala um odor semelhante ao do limão, que se torna mais intenso depois que a planta seca (MARTINS et al., 2003; IMIG; ZANCO, 2008).

A melissa encontra-se numa posição de destaque no rol das plantas medicinais devido à sua importância fitoterapêutica (SANGUINETTI, 1989). Esta espécie é utilizada popularmente para controlar crises nervosas, taquicardia, melancolia, histerismo e ansiedade.

O óleo essencial está presente nos tricomas secretores das folhas e flores e apresenta os compostos citral $\alpha$ e $\beta$ como majoritários, sendo estes os de maior interesse pela indústria farmacêutica devido à sua atividade antioxidativa, antimicótica, sedativa e antivirótica (TESKE; TRENTTINI, 1997; LORENZI; MATOS, 2002; HABER et al., 2005). Seu óleo apresenta outros compostos em menor quantidade como o citronelal, metilcitronelal, citronelol, pineno, limoneno e linalol. Também possui taninos, succínico, ácidos triterpenóides: (ursólico e oleânico), sesquiterpenos: (cariofileno), ácido caféico, ácidos rosmarínico, ácido clorogênico, flavonóides e substâncias amargas bem como glicosídeos flavônicos, mucilagens, alcalóides e resinas (LORENZI; MATOS, 2002; MAY et al., 2008).

O norte de Minas Gerais é uma área de confluência de biomas. Devido a esse ecótone as espécies vegetais ao serem introduzidas produzem metabólitos secundários como mecanismo de defesa contra os fatores bióticos e abióticos (TAIZ; ZEIGER, 2004).

O estudo do ciclo vegetativo dessa espécie determina a melhor época de colheita, de forma que permita o máximo aproveitamento e apresente melhor qualidade e o mínimo de perda para a comercialização. Pois suas propriedades químicas sofrem variação em diferentes regiões influenciada pelo cultivo, clima e sazonalidade.

Brant et al. (2009) afirmam a sensibilidade da melissa sobre intensidades elevadas de luz solar especificamente sobre exposição do fóton de luz vermelho. Entretanto, a condição do cultivo depende do produto a ser comercializado, pois a massa seca é favorecida em luz plena. Já o fóton de luz vermelha interfere negativamente na produção de óleo essencial.

Com base no acima exposto o objetivo desse estudo é avaliar o crescimento, produção de biomassa e teor de óleo essencial de Melissa officinalis L. nas condições climáticas de Montes Claros norte de Minas Gerais.

\section{Material e Métodos}

O experimento foi conduzido em casa de vegetação, no Instituto de Ciências Agrárias, Campus Regional de Montes Claros (ICA/UFMG), no período de 27 de maio a 21 de novembro de 2009. Localizado nas coordenadas geográficas: latitude $16^{\circ} 40^{\prime} 50,92$ "S e longitude $43^{\circ} 50^{\prime} 22,36^{\prime \prime} \mathrm{W}$, na altitude de $646,29 \mathrm{~m}$. O experimento foi realizado em duas etapas. A primeira avaliou-se o efeito da época de colheita sobre a produção de biomassa e de óleo essencial. As mesmas variáveis foram avaliadas na segunda etapa 30 dias após o primeiro corte.

O clima da cidade de Montes Claros, segundo a classificação de Köppen, Aw tropical de savana, com 
inverno seco e verão chuvoso (INMET, 2009). Os dados climatológicos da cidade de Montes Claros-MG, durante a condução do estudo, foram fornecidos pelo Instituto Nacional de Meteorologia instalado no ICA/UFMG (INMET, 2009). A temperatura da cidade no período do estudo manteve média de $24^{\circ} \mathrm{C}$, com mínima no mês de julho de $13^{\circ} \mathrm{C}$ e, a máxima no mês de setembro, de $38^{\circ} \mathrm{C}$.

As sementes de melissa foram fornecidas pela ISLA $^{\circledR}$, mantidas em ambientes úmido e resfriado a $10^{\circ} \mathrm{C}$ durante cinco dias para se hidratar e favorecer a germinação (RAMOS et al., 2002; TAIZ; ZEIGER, 2004). Após a quebra da dormência, foram semeadas três sementes por célula em bandeja de isopor com 200 células preenchidas com substrato Plantmax ${ }^{\circledR}$. A bandeja foi mantida em leito de enraizamento recebendo nebulização intermitente de água por 57 dias. O processo de germinação foi acompanhado diariamente. A porcentagem de germinação foi calculada através da fórmula: (número de sementes x 100) x (número de sementes germinadas) ${ }^{-1}$ (GRAZIANO et al., 1995).

As mudas foram aclimatizadas por três dias antes de serem transplantadas para os vasos. Aos 60 dias, com altura de 3 a $5 \mathrm{~cm}$, as mudas foram transplantadas para vasos com o volume de $3,5 \mathrm{~L}$. O substrato utilizado foi coletado na camada superficial do solo $(0-20 \mathrm{~cm})$ (SOUZA et al., 2003) no campus do ICA/UFMG, cujo resultado da análise química encontra-se na Tabela 1 . O solo foi peneirado em peneira de $4 \mathrm{~mm}$ e posteriormente misturado com esterco bovino curtido, também peneirado, na proporção $2: 1$, totalizando $350 \mathrm{~g}$ de esterco para cada $1050 \mathrm{~g}$ de solo por vaso.

Foram transplantadas duas mudas por vaso. A umidade dos mesmos foi mantida por meio de irrigações diárias. As plantas invasoras foram removidas manualmente, sempre que necessário.

O delineamento experimental utilizado foi o inteiramente casualizado com quatro épocas de colheitas como tratamentos e cinco repetições, totalizando 20 parcelas. Utilizou-se a metodologia quantitativa, onde os dados foram coletados no estágio vegetativo aos 40; 55; 70 e 85 dias após o transplantio (DAT), correspondendo aos dias 06/09, 21/09, 06/10 e 21/10/2009, respectivamente. A irrigação foi suspensa $24 \mathrm{~h}$ antes de cada colheita. As variáveis analisadas foram: o diâmetro do caule, o número de ramificações, a altura da parte aérea, a massa fresca, o rendimento de óleo essencial e a massa seca. Para a determinação do diâmetro do caule foi utilizado um paquímetro digital e, para a altura de parte aérea, foi utilizada uma régua graduada colocada desde o nível do solo até a inflexão da folha mais alta. Após essas medições as plantas foram separadas em caules e folhas para a realização da massa fresca e extração do óleo essencial. A extração do óleo foi realizada no Laboratório de Plantas Medicinais do ICA/UFMG, onde folhas frescas foram hidrodestiladas por $3 \mathrm{~h}$ em aparelho do tipo Clevenger, adaptado a um balão de fundo redondo com capacidade de $1.000 \mathrm{~mL}$ (MING et al., 1996). Após a extração, as folhas foram acondicionadas em saco de papel pardo e seco em estufa de circulação forçada, a $60^{\circ} \mathrm{C}$ até peso constante para a determinação da massa seca. $\mathrm{O}$ teor de óleo foi calculado com base na massa seca (CECONI et al., 2006).

TABELA 1: Análise química e física do solo utilizado como substrato no cultivo da Melissa officinalis, Montes Claros - MG, 2009.

\begin{tabular}{ccc}
\hline Atributos do Solo & Amostras & Nível \\
\hline pH em água & 7,7 & MA \\
P Mehlich $(\mathrm{mg} / \mathrm{kg})$ & 80,1 & $\mathrm{MB}$ \\
P remanescente $(\mathrm{ml} / \mathrm{L})$ & 35 & \\
$\mathrm{~K}(\mathrm{mg} / \mathrm{kg})$ & 679 & $\mathrm{MB}$ \\
$\mathrm{Ca}\left(\mathrm{cmolc} \mathrm{dm}^{-3}\right)$ & 8,9 & $\mathrm{MB}$ \\
$\mathrm{Mg}\left(\mathrm{cmolc}^{*} \mathrm{dm}^{-3}\right)$ & 2,6 & $\mathrm{MB}$ \\
$\mathrm{Al}\left(\mathrm{cmolc}^{*} \mathrm{dm}^{-3}\right)$ & 0 & $\mathrm{MBx}$ \\
$\mathrm{H}+\mathrm{AL}\left(\mathrm{cmolc}^{*} \mathrm{dm}^{-3}\right)$ & 0,76 & $\mathrm{MBx}$ \\
$\mathrm{SB}\left(\mathrm{cmolc} \mathrm{dm}^{-3}\right)$ & 13,2 & $\mathrm{MB}$ \\
$\mathrm{t}\left(\mathrm{cmolc} \mathrm{dm}^{-3}\right)$ & 13,2 & $\mathrm{MB}$ \\
$\mathrm{m}(\%)$ & 0 & $\mathrm{MBx}$ \\
$\mathrm{T}\left(\mathrm{cmolc} * \mathrm{dm}^{-3}\right)$ & 14 & $\mathrm{~B}$ \\
$\mathrm{~V}(\%)$ & 95 & $\mathrm{MB}$ \\
Mat. Org. $\left(\mathrm{dag}^{*} \mathrm{~kg}^{-1}\right)$ & 8,61 & $\mathrm{MB}$ \\
Areia grossa $\left(\mathrm{dag}^{*} \mathrm{~kg}^{-1}\right)$ & 8,5 & \\
Areia fina $\left(\mathrm{dag}^{*} \mathrm{~kg}^{-1}\right)$ & 67,5 & \\
Silte $\left(\mathrm{dag} * \mathrm{~kg}^{-1}\right)$ & 16 & $\mathrm{Ar}$ \\
Argila $\left(\mathrm{dag}^{*} \mathrm{~kg}^{-1}\right)$ & 8 & \\
\hline
\end{tabular}

$\mathrm{MBx}=$ muito baixo; $\mathrm{B}=$ bom; $\mathrm{Mb}=$ muito bom; $\mathrm{MA}=$ muito alto; $\mathrm{Ar}=$ argiloso. $\mathrm{P}=$ fósforo; $\mathrm{Ca}=$ cálcio; $\mathrm{Mg}=$ magnésio; $\mathrm{H}+\mathrm{AL}=$ acidez potencial; $\mathrm{SB}=$ soma de bases; $\mathrm{T}=$ capacidade de troca de cátion; $\mathrm{t}=$ capacidade de troca de cátion efetiva; Mat. Org. = matéria orgânica; $m \%$ = alta saturação por base; $\mathrm{V} \%$ = baixa saturação por base. 
O corte das plantas ocorreu entre 4 e $6 \mathrm{~cm}$ do solo (BUZATO, 2008). Após o primeiro corte, os vasos foram adubados com $350 \mathrm{~g}$ de esterco curtido. Após 30 dias do primeiro corte nos intervalos de 70, 85, 100 e 115 DAT foram repetidas as mesmas análises para a rebrota como: o diâmetro do caule, o número de ramificações, a altura da parte aérea, a massa fresca, o rendimento de óleo essencial e a massa seca. Os dados foram submetidos à análise de regressão utilizando o software SAEG (RIBEIRO JÚNIOR, 2001).

\section{Resultados e Discussão}

A germinação de sementes iniciou-se aos 10 dias após a semeadura, mantendo uma média de duas plântulas por dia, completando a germinação aos 20 dias após a semeadura. Atingindo um percentual de 17,5\% de sementes emergidas (GRAZIANO et al., 1995). Já no sul do Brasil, a germinação das sementes de melissa, alcançou 100\% aos 12 dias (IMIG; ZANCO, 2008). Tal diferença pode ser atribuída à sensibilidade da melissa às altas temperaturas do Norte de Minas atingindo até $38^{\circ} \mathrm{C}$.

As variáveis: altura, número de ramos, diâmetro do caule e massa fresca não variaram significativamente, enquanto a produção de massa seca foi influenciada significativamente, com redução da produção em colheitas com maior tempo (Figura 1).

$\mathrm{Na}$ rebrota, observou-se que as massas secas de folhas e de ramos não apresentaram diferença significativa entre os tratamentos. Diferente do resultado encontrado no primeiro corte na (Figura 1). Este resultado contradiz Aflatuni (2005), que em experimento com a mesma espécie observou que a massa seca não diferiu nas duas épocas de colheita, ou seja, no primeiro corte 30 dias após o transplantio e no segundo corte, 60 DAT. Já Monteiro (2009), observou o mesmo resultado para Mentha arvensis L. onde houve maior desenvolvimento vegetativo no primeiro corte aos 90 dias após o plantio quando comparado ao segundo, 90 dias após o primeiro. O que não se pode afirmar neste trabalho, devido ao fato da melissa ter sido submetida em tempos distintos para cada avaliação (corte e rebrota).

Segundo Blank et al. (2005) o motivo da massa seca não apresentar volume suficiente para que fossem observadas diferenças significativas, pode ser explicado através dos intervalos de corte. Os autores, afirmam que para obter uma avaliação da rebrota com êxito, o segundo corte tem que ser feito na $11^{\mathrm{a}}$ semana após o primeiro corte. Para eles a planta necessita de maior tempo de cultivo, permitindo assim o crescimento e

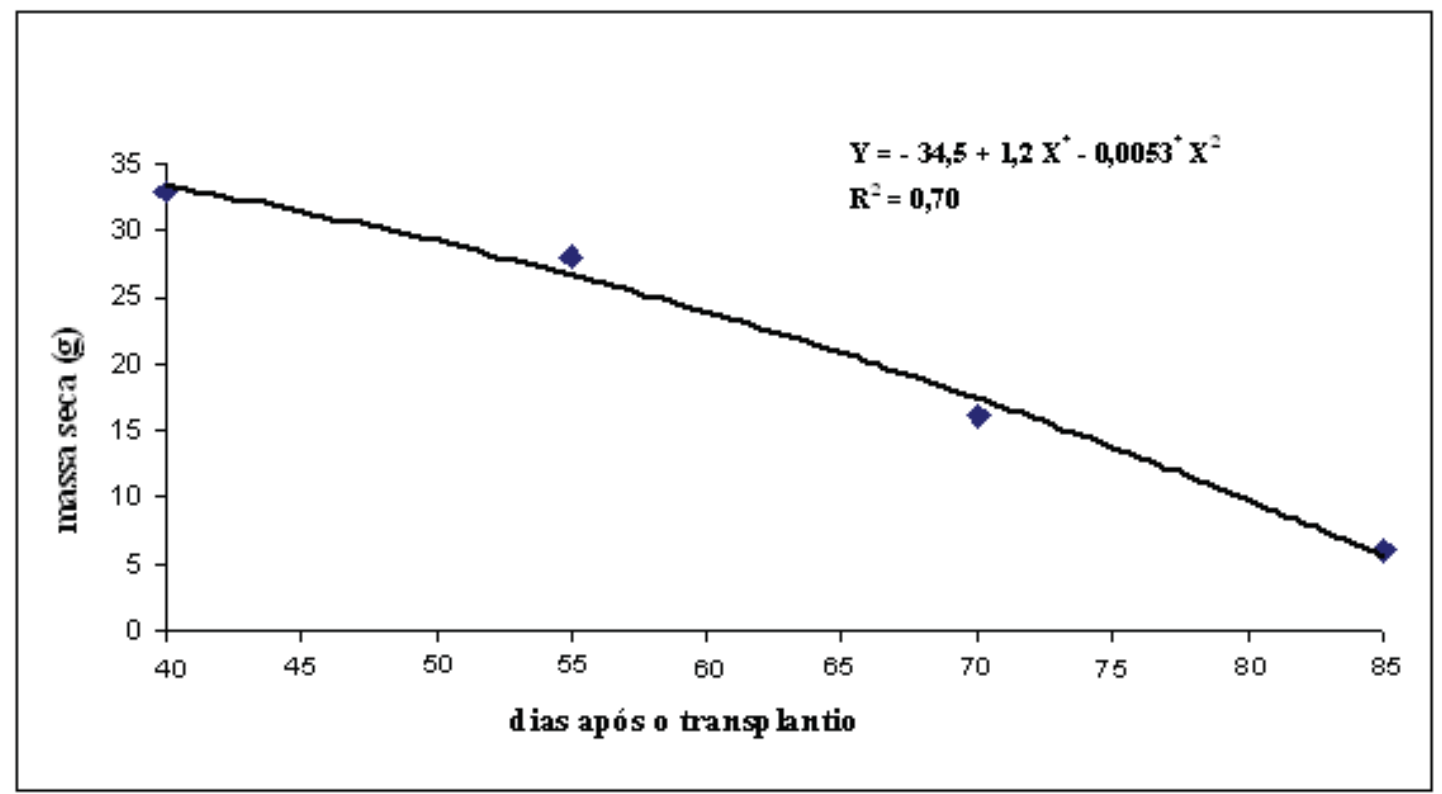

FIGURA 1: Produção de massa seca (g) em função da época de colheita da melissa (Melissa officinalis L.) cultivada em Montes Claros - MG.*: Significativo pelo teste t a $5 \%(\leq 0,05)$. 
emissão de área foliar. Porém os cortes realizados, não forma de acordo a sugestão dos autores acima, devido ao ciclo fenológico da espécie variar entre 90 e 120 dias conforme informações botânicas fornecidas por (LORENZI; MATOS, 2002). Segundo Smith (1962) e Scheffer-Basso et al. (2008), as plantas cortadas nesta época, rebrotam com mais vigor, em virtude de possuírem maior quantidade de fotoassimilados de reserva. Blank et al. (2005), estudando a espécie em condições de casa de vegetação, obtiveram dois cortes por ciclo, não sendo possível o terceiro corte em razão da alta mortalidade de plantas.

O teor de óleo essencial, não apresentou diferença significativa entre as épocas avaliadas, sendo que a média do teor de óleo no primeiro corte foi de $0,01826 \%$ e no segundo corte $0,01815 \%$. O resultado indica que as colheitas realizadas com maior biomassa são as mais favoráveis, o que ocorreu com o menor período entre o transplantio e a colheita. Pois, na rebrota a planta com menor área foliar, ou seja, menor tempo de cultivo pode apresentar a mesma quantidade de óleo essencial quando comparado aos demais tratamentos cultivado por mais tempo, além de maior produção de massa seca, conforme mostra a Figura 2.

Resultado semelhante foi observado por May et al. (2008), cultivando a mesma espécie, onde os maiores rendimentos de massa seca corresponderam ao maior intervalo de corte. A variação do teor de óleo em função da idade da planta parece ser um fator que varia com a espécie, pois em Ocimum gratissimum L. a maior produção de óleo essencial, ocorreu aos 83 dias (ROCHA et al., 2005), enquanto para Cymbopogon citratus D.C. foi observado um decréscimo gradual no teor de óleo com a idade da planta (LEAL et al., 2003). Siqueira (2006) fez a mesma observação em Lippia sidoides Cham., no qual o teor máximo de óleo foi aos 180 dias, na primeira época de colheita. Já Santos e Innecco (2004), em experimento com Lippia alba Mill., avaliaram duas épocas de colheita, sendo estas aos 60 e 120 DAT, na qual a última época apresentou o maior rendimento de óleo.

Czepak (1998) observou o melhor rendimento de óleo aos 60 e 70 dias após o transplantio da Mentha arvensis L., porém, ocorreram alterações nos teores de mentol neste intervalo de colheita.

Contudo, para o primeiro corte em cultivos de melissa, o rendimento de óleo não houve alteração em diferentes épocas de colheita após o transplantio.

Em relação ao teor de óleo essencial observado na rebrota (Figura 2), o maior teor ocorreu aos 70 dias, com um rendimento de $0,029 \%$, decrescendo linearmente a partir daí. Este resultado concorda com o observado por

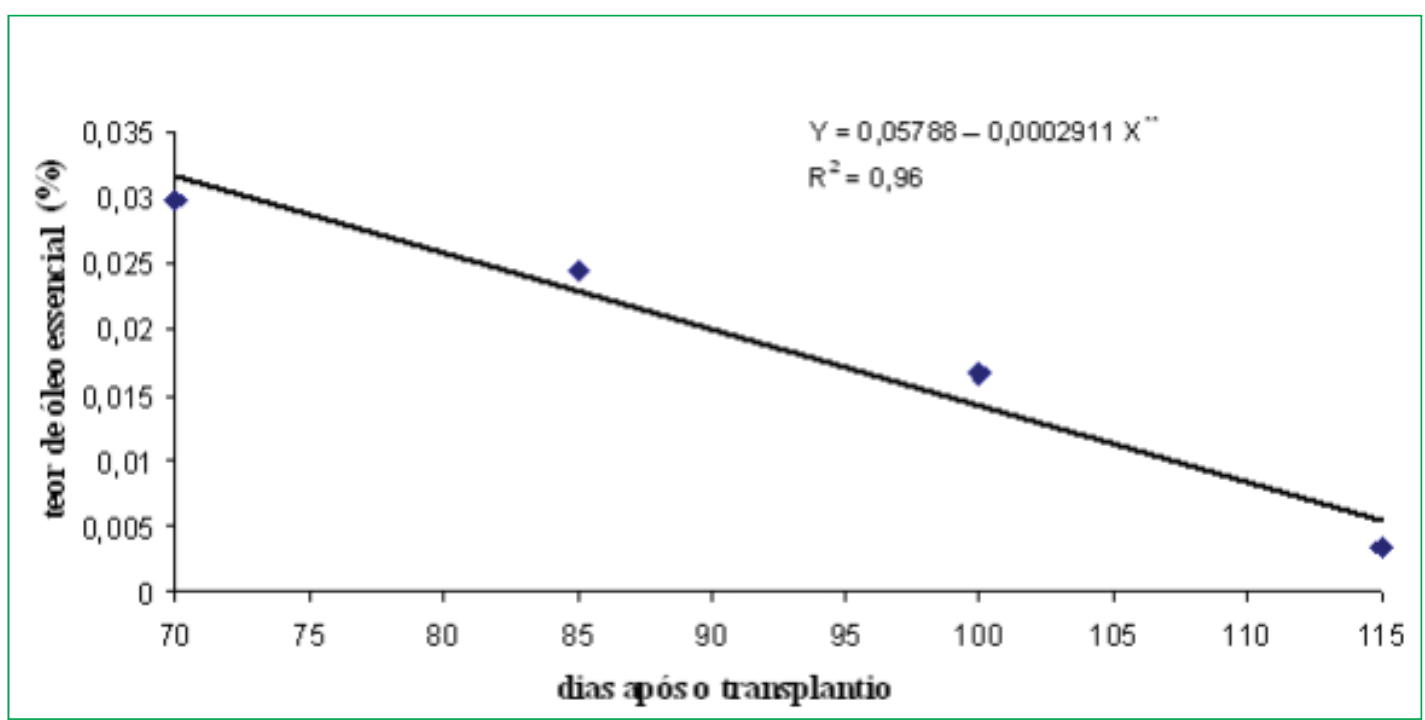

FIGURA 2: Teor de óleo essencial com base na massa seca (g) em função da época de colheita na rebrota da melissa (Melissa officinalis L.) cultivada em Montes Claros - MG.**: Significativo pelo teste t a $1 \%$ de probabilidade. 
Ming (1998), em trabalhos com Lippia alba. O autor observou que o óleo foi diminuindo de acordo a colheita realizada em intervalos mais longos. À medida que as atividades fisiológicas se encerram, a planta entra num estágio de senescência, encerrando a biossíntese de óleo essencial nas partes mais velha. Sendo necessária a emissão de novas brotações para ocorrer a produção dos óleos essenciais nas porções mais jovens da planta.

O número de ramos na rebrota (Figura 3 ) apresentou aumento linear, pois à medida que a planta se desenvolve, há uma tendência em aumentar o número de brotações.

Com isso, o maior número de brotos e galhos influenciou na massa fresca (Figura 4) apresentando um comportamento quadrático, sendo o máximo de área foliar estimado aos 98 DAT.

Assim, para comercialização da melissa fresca, a rebrota aos 98 dias é o ponto de colheita, embora a qualidade do material tenha sensível redução no teor de óleo essencial. Este comportamento, em que a maior

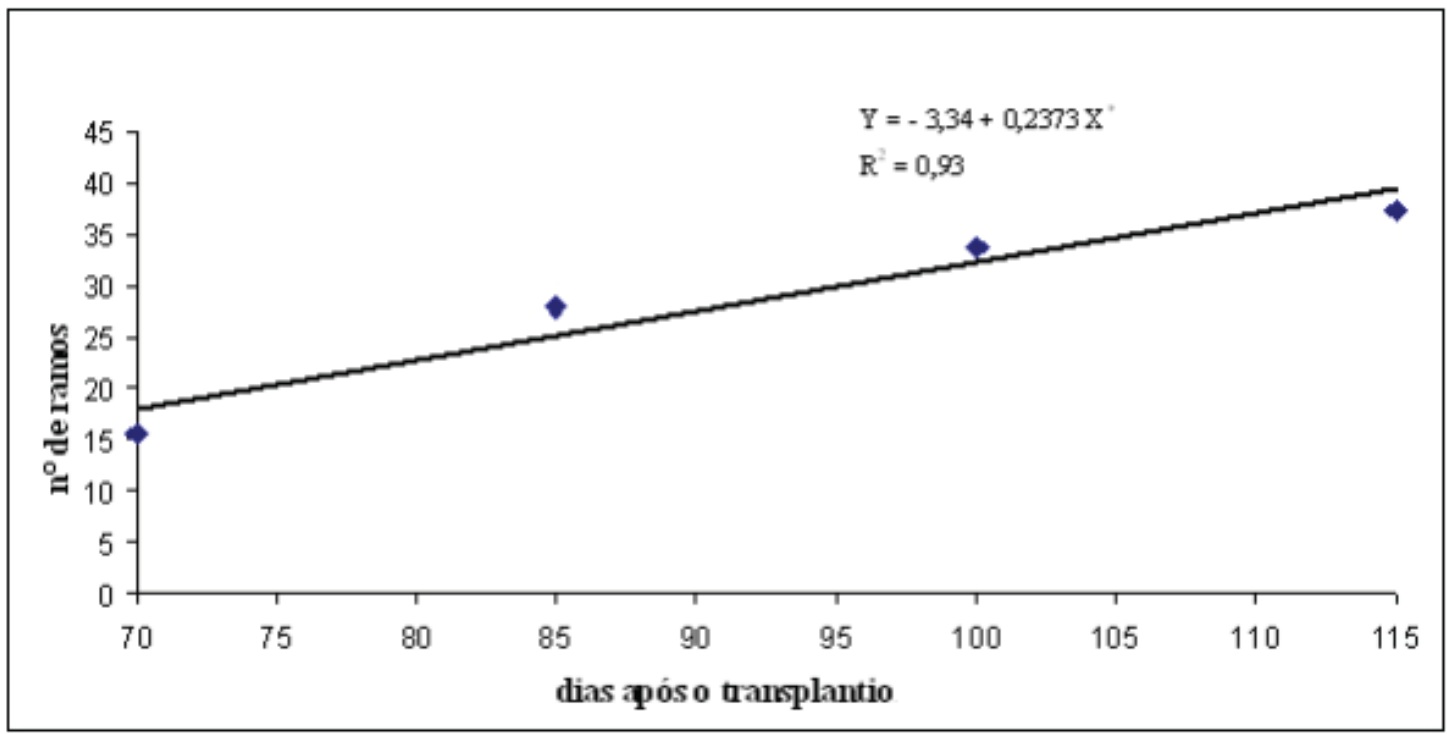

FIGURA 3: Número de ramos em função da época de colheita na rebrota da melissa (Melissa officinalis L.) cultivada em Montes Claros - MG.*: Significativo pelo teste t a $5 \%$ de probabilidade.

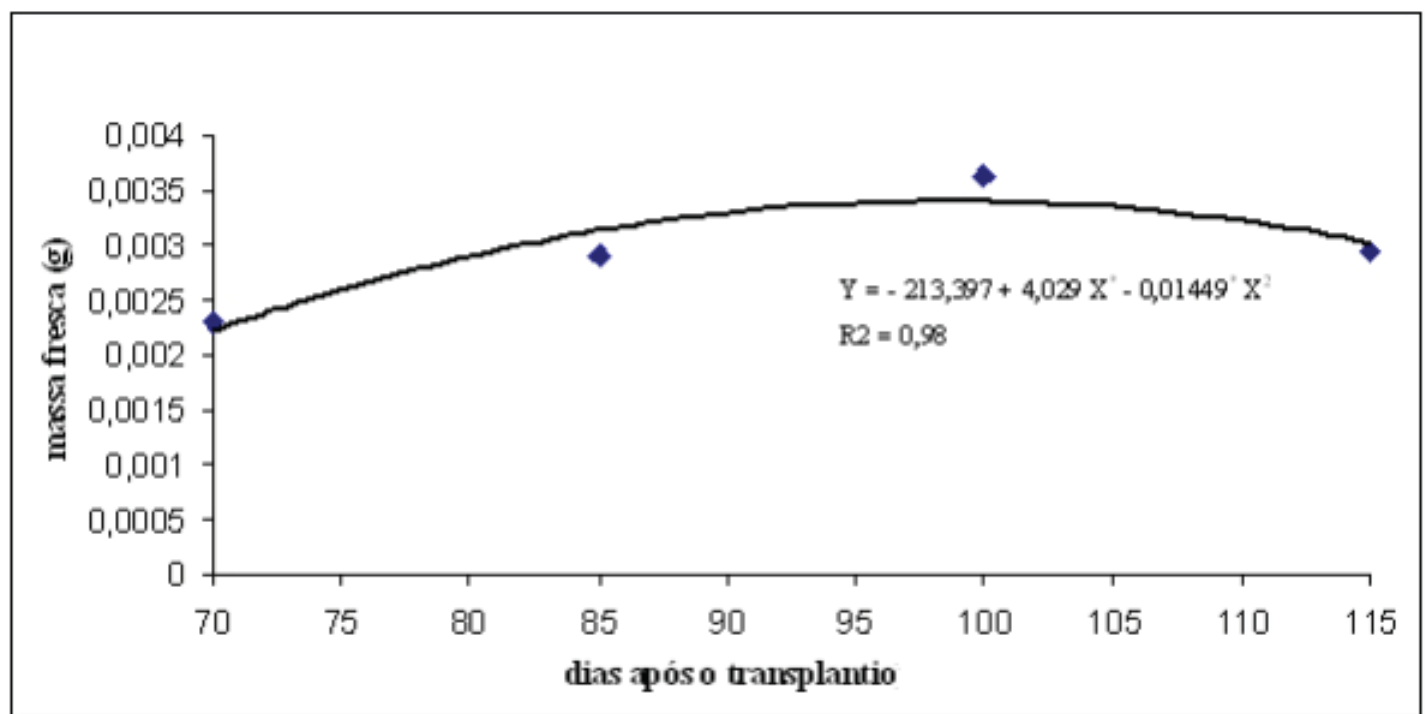

FIGURA 4: Produção de massa fresca (g) em função da época de colheita na rebrota da melissa (Melissa officinalis L.) cultivada em Montes Claros - MG.*: Significativo pelo teste t a $5 \%$ de probabilidade. 
produção de massa fresca está relacionada com menor produção de metabólitos secundários ao longo do cultivo, é explicado pelo fato da planta já ter atingido a idade adulta. Apesar de não florescer no Brasil, com esta idade a espécie já está completando o seu ciclo ou entrando em estágio de senescência, não sendo mais necessário investir em defesa química com a mesma intensidade de uma planta jovem.

Com este trabalho conclui-se que a colheita mais precoce favorece a produção de biomassa nas condições do Norte de Minas mantendo o teor de óleo essencial similar às demais colheitas. As plantas com menor idade na primeira colheita apresentaram maior produção de teor de óleo essencial em relação ao material colhido na rebrota, sendo que a produção de massa fresca foi favorecida pelas colheitas mais tardias. Entretanto, recomenda-se ao produtor efetuar podas em sua plantação a fim de aumentar a área foliar e obter mais cortes para a comercialização da massa fresca e seca, sua principal fonte de renda no mercado de chás.

\section{Referências}

AFLATUNI, A. The yield and essential content of mint (Mentha ssp.) in northern Ostrobothnia. 2005. $50 \mathrm{f}$. Dissertation (Master) - University of Oulu, Oulu. 2005.

BLANK, A. F.; FONTES, S. M.; OLIVEIRA, A. S. O.; MENDONÇA, M. C.; SILVA-MANN, R.; ARRIGONI-BLANK, M. F. Produção de mudas, altura e intervalo de corte em melissa. Horticultura Brasileira, Campinas, v. 23, n. 3, p. 780-784, 2005.

BRANT, R. S.; PINTO, J. E. B. P.; ROSA, L. F.; ALBUQUERQUE, C. J. B.; FERRI, P. H.; CORREA, R. M. Crescimento, teor e composição do óleo essencial de melissa cultivada sob malhas fotoconversoras, Ciência Rural, Santa Marina, v. 39, n. 5, p. 14011407, 2009.

BUZATO, A. T. F. Avaliação da produção de forragem, biomassa da rebrota e valor protéico da aveia IPR 126 submetida a cortes e doses de calxisto. 2008. 25 f. Monografia (Graduação em Engenharia Agronômica) - Universidade Estadual de Ponta Grossa, Ponta Grossa, 2008.

CECONI, D. E.; POLETTO, I.; BRUN, E. J.; LOVATO, T. Crescimento de mudas de açoita-cavalo (Luehea divaricata Mart.) sob influência da adubação fosfatada. Nota Técnica Cerne, Lavras, v. 12, n. 3, p. 292-299, 2006.

CORREA JÚNIOR, C.; MING, L. C.; SCHEFFER, M. C. Cultivo de plantas medicinais, condimentares e aromáticas. 2. ed. Jaboticabal: FUNEP, 1994. 162 p.

COUTO, M. E. O. Coleção de plantas medicinais aromáticas e condimentares. Pelotas: Documento 157 (on-line) - Embrapa, 2006. $91 \mathrm{p}$.
CZEPAK, M. P. Produção de óleo bruto e mentol cristalizável em oito freqüências de colheita da menta (Mentha arvensis L.). In: MING, L. C. (Ed.). Plantas medicinais aromáticas e condimentares - avanços na pesquisa agronômica. Botucatu: UNESP, 1998. p. 53-80.

GRAZIANO, T. T.; DEMATTÊ, J. B. I.; VOLPE, C. A.; PERECIN, D. Interação entre substratos e fertilização na germinação e produção de mudas de Tagetes pátula L. (Compositae). Revista Brasileira de Horticultura Ornamental, Campinas, v. 1, n. 2, p. 78-85, 1995.

HABER, L. L.; LUZ, J. M. Q.; ARVATIDÓRO, L. F.; SANTOS, J. E. Diferentes concentrações de solução nutritiva para o cultivo de Mentha piperita e Melissa officinalis. Horticultura Brasileira, Campinas, v. 23, n. 4, p. 1006-1009, 2005.

INMET. 2009. Disponível em: <http://www.inmet.gov.br>. Acesso em: 15 maio 2009.

IMIG, C. D.; ZANCO, J. J. Teste de adubação para plantas com atividade medicinal. Relatório de projeto de pesquisa. Método de pesquisa em fertilidade do solo, protocolo: 2351. Tubarão: UNISUL, 2008. 23 p.

LEAL, T. C. A. B.; FREITAS, S. P.; SILVA, J. F.; CARVALHO, A. J. C. Produção de biomassa e óleo essencial em plantas de capimcidreira (Cymbopogon citratus (Dc.) Stapf.) em diferentes idades. Revista Brasileira de Plantas Medicinais, Botucatu, v. 5, n. 2, p. 61-64, 2003.

LORENZI, H.; MATOS, F. J. A. Plantas medicinais do Brasil: nativas e exóticas. Nova Odesa: Plantarum, 2002. 544 p.

MARTINS, E. R.; CASTRO, D. M.; CASTELLANI, D. C.; DIAS, F. E. Plantas medicinais. Viçosa: UFV, 2003. 220 p.

MAY, A.; BOVI, O. A.; SACCONI, L. V.; SAMRA, A. G.; PINHEIRO, M. Q. Produtividade da biomassa de melissa em função de intervalo de cortes e doses de nitrogênio. Horticultura Brasileira, Campinas, v. 26, n. 3, p. 312-315, 2008.

MING, L. C.; FIGUEIREDO, R. O.; MACHADO, S. R.; ANDRADE, R. M. C. Yeld of essential oil and citral content in different parts of lemongrass leaves (Cymbopongon citratus (D.C) Stapf.) Poaceae. Acta Horticulturae, Amsterdam, v. 426, p. 555559, 1996.

MING, L. C. Adubação orgânica no cultivo de Lippia alba (MIll.) N. E. Br - Verbenaceae. In: MING, L. C.; SCHEFFER, M. C.; CORREA JR., C.; BARROS, I. B. I.; MATTOS, J. K. A. (Org.). Plantas medicinais, aromáticas e condimentares - avanços na pesquisa agronômica. v. 1, 1. ed. Botucatu: CEPLAM/UNESP, 1998. p.165-191.

MONTEIRO, R. Desenvolvimento de menta e produção de óleo essencial sob diferentes condições de manejo. 2009. $81 \mathrm{f}$. Dissertação (Mestrado em Agronomia) - Universidade Federal do Paraná, Curitiba. 2009.

RAMOS, J. D.; CHALFUM, N. N. J.; PASQUAL, M.; RUFINI, J. C. M. Produção de mudas de plantas frutíferas por sementes, Informe Agropecuário, Belo Horizonte, v. 23, n. 216, p. 64-72, 2002.

RIBEIRO JÚNIOR, J. I. Análises estatísticas no SAEG. Viçosa: UFV, 2001. 301 p.

ROCHA, G. S.; CASTEllani, D. C.; DALl'OGLiO, E. L. Análise de crescimento, caracterização e produção de óleo essencial em alfavaca-cravo (Ocimum gratissimum L.) no município de 
Cáceres, MT. In: Simpósio Brasileiro de Óleos Essenciais, 3, 2005, Campinas. Anais... Campinas: SBOE, 2005, Campinas. p. 110.

SANGUINETTI, E. E. Plantas que curam. Porto Alegre: Rigel, 1989. 208pp.

SANTOS, M. R. A.; INNECCO, R. Adubação orgânica e altura de corte da erva-cidreira brasileira. Horticultura Brasileira, Campinas, v. 22, n. 2, p. 182-185, 2004.

SCHEFFER-BASSO, S. M.; LUBENOW, R.; CARNEIRO, C. M.; CHINI, S. O. Morfofisiologia da rebrota de Baccharis trimera (Less) DC., Asteraceae: subsídios para seu controle em pastagens naturais. Revista Biotemas, Florianópolis, v. 21, n. 3, p. 31-37, 2008.

SIQUEIRA, C. F. Efeito da época de colheita na produção de biomassa e de óleo essencial do alecrim-pimenta (Lippia sidoides
Cham). 2006. 23 f. Monografia (Graduação) - Universidade Federal de Minas Gerais, Belo Horizonte, 2006.

SMITH, D. Carbohydrates root reserves in alfalfa, red clover and birdsfoot trefoil under management schedules. Crop Science, Madison, v. 2, p. 75-78. 1962.

SOUZA, C. A. S.; CORREIA, F. L. O.; MENDONÇA, V.; CARVALHO, J. G. Crescimento de mudas de gravioleira (Anonna muricata L.) em substrato com superfosfato simples e vermicomposto. Revista Brasileira de Fruticultura, Jaboticabal, v. 25, n. 3, p. $453-456,2003$.

TAIZ, L.; ZEIGER, E. 2004. Fisiologia vegetal. 3. ed. Porto Alegre: ARTMED, 2004. $719 \mathrm{p}$.

TESKE, M.; TRENTTINI A. M. M. Compêndio de Fitoterapia. Curitiba: Herbarium, 1997. 317 p. 